\title{
Urinary incontinence in middle aged women: childhood enuresis and other lifetime risk factors in a British prospective cohort
}

\author{
Diana Kuh, Linda Cardozo, Rebecca Hardy
}

\begin{abstract}
Study objective-To investigate the prevalence and lifetime risk factors for urinary incontinence in middle aged women.

Design-Nationally representative birth cohort study with prospective data on childhood enuresis, measured adult height and weight, childbearing histories and measures of socioeconomic status updated at regular contacts, and measures of menopausal status, symptomatology and health care in midlife.

Setting-England, Scotland and Wales.

Participants-General population sample of 1333 women aged 48 years.

Main results-Fifty per cent reported symptoms of stress incontinence and $22 \%$ reported symptoms of urge incontinence in the previous year. Eight per cent had severe symptoms. Women who at age 6 years had wet in the day or several nights a week were more likely to suffer severe incontinence and report urge symptoms but occasional bedwetting was not associated with an increased risk in adult life. Those who were older at the birth of their children and who had vaginal deliveries had an excess risk of stress symptoms. Heavier adult body weight was also a risk factor for these symptoms and for severe incontinence. Postmenopausal women were less likely to report stress symptoms. These risk factors remained significant after taking account of the increased reporting of incontinence among women with high levels of general symptomatology and general practioner visits, and of stress symptoms among better educated women. Conclusions-Urinary incontinence is a common problem among middle aged women. This is the first prospective study of a general population sample to support the postulated link between childhood enuresis and adult incontinence. Childbearing has long term adverse effects, particularly for older mothers. Overweight is a common risk factor.

(F Epidemiol Community Health 1999;53:453-458)
\end{abstract}

Urinary incontinence is a common problem among middle aged women. ${ }^{1-11}$ The purpose of this paper is to investigate lifetime risk factors for urinary incontinence in women participating in a cohort study that has followed up a representative sample of the general population since their birth in 1946 until middle age. Prospective information is available on childhood enuresis and, in adulthood, on childbearing, a history of kidney and bladder problems, body weight, hysterectomy and menopausal status, which previous general population studies have suggested are related to incontinence in midlife. ${ }^{1389}{ }^{12-16}$

\section{Methods}

The Medical Research Council National Survey of Health and Development is a socially stratified cohort of 2548 women and 2814 men followed up 19 times between their birth in March 1946 and the age of 43 years. ${ }^{17-19}$ When they were 47 years old a postal questionnaire was sent to 1778 women study members with whom the team was still in regular contact to obtain information about the timing of the menopause, health changes, and use of hormone replacement therapy. ${ }^{20}$ Of the original cohort $6 \%$ had died, $12 \%$ had refused to take part at earlier follow ups, and 13\% could not be traced. The first postal questionnaire was completed and returned by 1498 women giving a response rate of $84 \%$. The second postal questionnaire, when the women were 48 years old, asked a series of questions about their experience of incontinence and was sent to 1486 women who had completed the first year's questionnaire: the response rate was $93 \%$ (1378) for this questionnaire.

INCONTINENCE AND OTHER URINARY SYMPTOMS In the second postal questionnaire, specific questions designed to identify women with symptoms of stress and urge incontinence and to estimate the severity of incontinence were answered by 1333 women (97\% of those who returned the questionnaire). Severe incontinence was defined as occurring twice a month or more over the previous year and the reported loss of more than a few drops of urine. Women were classified as moderately incontinent if they reported one but not both of these symptoms. These groups were distinguished from other women who reported milder levels of incontinence or none at all.

Women who replied positively to the question "Do you ever lose any urine when you cough, sneeze, laugh, run or exercise?" were classified as having symptoms of stress incontinence (hereafter known as stress symptoms). Those who replied positively both to the question "Do you ever have an urgent and strong desire to pass urine which is difficult to control?" and to the follow up question "Do you ever lose any urine before you reach the toilet?" were classified as having symptoms of urge incontinence (hereafter known as urge symptoms). Women were 
Table 1 Prevalence of urinary symptoms

\begin{tabular}{|c|c|c|c|c|c|}
\hline & $\begin{array}{l}\text { Severe incontinence } \\
(n=107) \%\end{array}$ & $\begin{array}{l}\text { Urge symptoms } \\
(n=299) \%\end{array}$ & $\begin{array}{l}\text { Stress symptoms } \\
(n=665) \%\end{array}$ & $\begin{array}{l}\text { No incontinence } \\
(n=603) \%\end{array}$ & $\begin{array}{l}\text { All women } \\
(n=1333) \%\end{array}$ \\
\hline Frequency $\geqslant 2$ hourly & 25.2 & 18.1 & 11.9 & 7.0 & 9.9 \\
\hline Nocturia $\geqslant 2$ & 29.0 & 22.4 & 16.8 & 11.9 & 14.6 \\
\hline Dysuria & 15.1 & 10.5 & 6.5 & 3.7 & 5.0 \\
\hline \multicolumn{6}{|c|}{ Uses pads for incontinence } \\
\hline occasionally & 32.7 & 21.7 & 17.3 & $\mathrm{n} / \mathrm{a}$ & 8.9 \\
\hline frequently & 29.9 & 11.7 & 8.7 & & 4.5 \\
\hline \multicolumn{6}{|c|}{ Bothered by incontinence in everyday life } \\
\hline a little & 43.9 & 36.8 & 28.7 & $\mathrm{n} / \mathrm{a}$ & 15.5 \\
\hline a lot & 29.9 & 14.7 & 9.0 & & 4.7 \\
\hline
\end{tabular}

asked how often they passed urine during the day and night, and if they used pads to protect against the loss of urine. Urinary frequency during the day was defined as at least two hourly and nocturia as at least twice a night. They were also asked whether in the last year they had experienced pain on urination (dysuria) or had been bothered by incontinence in their everyday life, how long they had suffered from incontinence and what, if anything, they thought had caused its occurrence.

POTENTIAL RISK FACTORS AND CONFOUNDERS Childhood enuresis was defined from maternal reports of bedwetting "occasionally" or at least "several nights a week" or wetting "sometimes" during the day when study members were 6 years old.

Information on the birth of children was updated at each adult home visit (the last one occurring when survey members were 43 years old) and was available for 1239 women. In addition, in the third postal questionnaire (at 49 years), women were asked to recall the number of caesarean deliveries-this was obtained for 1057 women.

Body mass index was derived from measurements of height and weight taken at 43 years by research nurses using portable stadiometers and scales and the same standardised conditions as used at previous contacts. ${ }^{21}$ Using the same criteria as the Health Survey for England, ${ }^{22}$ women were classified according to their body mass index as either underweight $(<20.0)$, of normal weight (20.1-25.0), overweight (25.1-30.0) or obese (>30.0).

Women with a history of kidney or bladder infections, such as cystitis, were identified from answers to a list of health problems completed by research nurses at the home visit when survey members were 43 years old.

Women reporting an absence of menstruation for more than 12 months $(8 \%)$ at the age of 48 years were classified as postmenopausal and those who reported less regular periods or an absence of menstruation for between 3 to 12 months $(39 \%)$ as perimenopausal; a quarter $(26 \%)$ were still premenopausal. ${ }^{20}$ Women whose menopausal status could not be classified either because they were receiving hormone replacement therapy (HRT) that they had started taking before they were postmenopausal $(10 \%)$ or because they had had a hysterectomy $(17 \%)$ were studied separately.

We hypothesised that women who perceived their health was poor or who utilised health care resources regularly might report incontinence more often. A measure of self reported health was obtained by deriving a score from a checklist of 20 common symptoms given at 47 and 48 years. ${ }^{20}$ Symptoms that had bothered the women a little over the past 12 months were scored 1 and those that had bothered them a lot were scored 2 . The scores for each year were standardised to give a mean of 0 and a standard deviation of 1 , and then added together to give a total symptom score. The number of consultations with the family doctor over the past 12 months was used as a measure of health care utilisation.

Reports of incontinence may also be affected by socioeconomic status and this was assessed by the highest educational and training qualifications achieved by 26 years, classified by the Burnham scale ${ }^{23}$ and grouped into no qualifications (32\% of women), less than O level (9\%), O level or equivalent $(28 \%)$, A level or equivalent $(25 \%)$ or degree level or equivalent $(6 \%)$.

STATISTICAL ANALYSIS

Risk factors for stress and urge symptoms and for severe incontinence are investigated using $\chi^{2}$ tests. Factors that were significant at the $10 \%$ level were included in the logistic regression analyses to identify the most powerful predictors of stress and urge symptoms and severe incontinence. Body mass index rather than the four categories of body weight was entered into these models as a continuous variable. The results are presented for unweighted data as weighting the sample to allow for the original sample stratification had no appreciable effects on the findings.

\section{Results}

At 48 years over half the women (55\%) reported some incontinence in the past 12 months. Eight per cent had severe symptoms, $15 \%$ moderate symptoms and almost a third $(32 \%)$ had only mild symptoms. Over one in five women $(22 \%)$ suffered urge symptoms and half $(50 \%)$ suffered stress symptoms. A fifth $(20 \%)$ of the whole sample and three fifths $(60 \%)$ of those with severe incontinence reported both stress and urge symptoms. Table 1 shows the prevalence of other urinary symptoms and the extent to which incontinence bothered the women in everyday life.

For two fifths (39\%) of women their urinary incontinence had started in the past year, for a further two fifths $(40 \%)$ the problem had started in the past five years and for one fifth (19\%) the problem had begun more than five years previously. In response to the question of what caused their incontinence, pregnancy and childbirth were the most common reasons given (unprompted) as the underlying cause 
Table 2 Percentage of women aged 48 years reporting stress symptoms, urge symptoms and severe incontinence according to various characteristics

\begin{tabular}{|c|c|c|c|}
\hline & $\begin{array}{l}\text { Stress } \\
\text { symptoms \% }\end{array}$ & $\begin{array}{l}\text { Urge } \\
\text { symptoms \% }\end{array}$ & $\begin{array}{l}\text { Severe } \\
\text { incontinence \% }\end{array}$ \\
\hline \multicolumn{4}{|l|}{ Childhood enuresis (6 y) } \\
\hline Dry during the day and night (1126) & 49.8 & 22.3 & 7.6 \\
\hline Wet occasionally at night (47) & 42.6 & 19.1 & 6.4 \\
\hline Wet sometimes in day, dry at night (31) & 51.6 & 32.3 & 12.9 \\
\hline Wet several nights a week, dry in day (9) & 66.7 & 33.3 & 22.2 \\
\hline Wet several nights a week and during day (13) & 38.5 & 53.8 & 23.1 \\
\hline $\mathrm{p}$ value for $\chi^{2}$ test & 0.609 & 0.044 & 0.096 \\
\hline \multicolumn{4}{|l|}{ Number of children } \\
\hline None (158) & 36.7 & 17.0 & 3.8 \\
\hline $1(160)$ & 55.6 & 30.6 & 7.5 \\
\hline $2(570)$ & 49.8 & 23.5 & 8.2 \\
\hline $3(259)$ & 53.3 & 23.9 & 9.3 \\
\hline $4+(92)$ & 52.2 & 15.2 & 12.0 \\
\hline $\mathrm{p}$ value for $\chi^{2}$ test ${ }^{\star}$ & 0.016 & 0.734 & 0.016 \\
\hline \multicolumn{4}{|l|}{ Age at birth of 1 st child (by 43 y) } \\
\hline $14-21(324)$ & 51.5 & 23.8 & 8.6 \\
\hline $22-24(297)$ & 47.8 & 24.9 & 9.8 \\
\hline $25-30(374)$ & 52.9 & 22.2 & 8.0 \\
\hline $31 \mathrm{y}$ or more $(87)$ & 60.9 & 28.7 & 8.0 \\
\hline $\mathrm{p}$ value for $\chi^{2}$ test ${ }^{\star}$ & 0.183 & 0.622 & 0.698 \\
\hline \multicolumn{4}{|l|}{ Age at birth of last child (by $43 \mathrm{y}$ ) } \\
\hline $14-21$ yrs $(63)$ & 49.2 & 30.2 & 6.3 \\
\hline $22-24$ yrs (194) & 46.9 & 22.2 & 9.3 \\
\hline $25-30$ yrs (493) & 51.7 & 24.5 & 8.5 \\
\hline $31 \mathrm{y}$ or more $(332)$ & 55.1 & 22.9 & 9.0 \\
\hline $\mathrm{p}$ value for $\chi^{2}$ test ${ }^{\star}$ & 0.088 & 0.508 & 0.707 \\
\hline \multicolumn{4}{|l|}{ Type of delivery } \\
\hline All caesarean deliveries (45) & 44.4 & 22.2 & 6.7 \\
\hline Vaginal and caesarean deliveries (57) & 49.1 & 31.6 & 5.3 \\
\hline Vaginal deliveries only (955) & 52.1 & 22.6 & 8.5 \\
\hline $\mathrm{p}$ value for $\chi^{2}$ test $t^{\star}$ & 0.281 & 0.512 & 0.444 \\
\hline \multicolumn{4}{|l|}{ History of kidney infections (up to $43 \mathrm{y}$ ) } \\
\hline No $(1133)$ & 48.1 & 21.8 & 7.1 \\
\hline Yes (200) & 56.9 & 28.1 & 11.5 \\
\hline $\mathrm{p}$ value for $\chi^{2}$ test & 0.111 & 0.034 & 0.021 \\
\hline \multicolumn{4}{|l|}{ Menopausal status (48 y) } \\
\hline Premenopausal (480) & 49.8 & 18.1 & 7.3 \\
\hline Perimenopausal (319) & 52.7 & 23.8 & 6.0 \\
\hline Postmenopausal (102) & 36.3 & 18.6 & 9.8 \\
\hline Hysterectomy (205) & 53.7 & 28.8 & 9.8 \\
\hline HRT $(125)$ & 47.9 & 21.0 & 5.0 \\
\hline $\mathrm{p}$ value for $\chi^{2}$ test & 0.042 & 0.025 & 0.344 \\
\hline \multicolumn{4}{|l|}{ Weight at $43 \mathrm{y}$} \\
\hline Under weight (88) & 44.3 & 22.7 & 2.3 \\
\hline Normal weight (688) & 47.5 & 21.8 & 5.7 \\
\hline Overweight (307) & 55.0 & 23.1 & 12.7 \\
\hline Obese (147) & 54.4 & 30.6 & 13.6 \\
\hline $\mathrm{p}$ value for $\chi^{2}$ test ${ }^{\star}$ & 0.016 & 0.064 & $<0.001$ \\
\hline \multicolumn{4}{|l|}{ Recent symptomatology (quintiles) } \\
\hline Least symptoms (264) & 37.5 & 11.4 & 3.4 \\
\hline $2(263)$ & 47.1 & 17.9 & 5.3 \\
\hline $3(274)$ & 49.3 & 18.6 & 6.2 \\
\hline $4(259)$ & 54.8 & 25.9 & 10.0 \\
\hline Most symptoms (272) & 60.7 & 38.2 & 15.1 \\
\hline $\mathrm{p}$ value for $\chi^{2}$ test ${ }^{\star}$ & $<0.001$ & $<0.001$ & $<0.001$ \\
\hline \multicolumn{4}{|l|}{ GP consultations in 12 months } \\
\hline No more than $2(870)$ & 45.5 & 18.7 & 5.6 \\
\hline 3 or more $(432)$ & 57.9 & 29.6 & 12.3 \\
\hline $\mathrm{p}$ value for $\chi^{2}$ test & $<0.001$ & $<0.001$ & $<0.001$ \\
\hline \multicolumn{4}{|l|}{ Educational qualifications } \\
\hline Degree (77) & 64.9 & 23.4 & 5.2 \\
\hline A levels (315) & 55.6 & 22.2 & 5.1 \\
\hline O levels (350) & 52.9 & 23.4 & 8.6 \\
\hline Less than O level (110) & 46.4 & 20.5 & 10.0 \\
\hline None (409) & 41.8 & 23.0 & 11.0 \\
\hline $\mathrm{p}$ value for $\chi^{2}$ test ${ }^{\star}$ & $<0.001$ & 0.996 & 0.003 \\
\hline
\end{tabular}

*test for trend.
KEY POINTS

- In a representative sample of 1333 British women aged 48 years $55 \%$ reported urinary incontinence in the past year.

- Women with incontinence reported more health symptoms and visited their GPs more often than other women.

- They were also more likely to be overweight.

- Women with severe incontinence (8\%) and those with urge symptoms (22\%) were more likely to have suffered regular enuresis in childhood. This is the first large prospective study to demonstrate this finding.

- Stress symptoms (reported by 50\%) were strongly associated with normal deliveries after age 30 years.

RISK FACTORS FOR STRESS SYMPTOMS

Stress symptoms were less common among nulliparous women but there was no trend according to the number of children if these women were excluded (table 2). Women who had had their first child or last child after 30 years of age reported these symptoms more than other women but they were less common among the small number who had delivered all their children by caesarean section. Type of delivery and age at first birth were not significant factors but all these aspects of childbearing were highly correlated in ways that could confound any relations with incontinence: for example, those who were older when they began their families were more likely to have a caesarean delivery and to have smaller families. Thus aggregate variables were derived (see table 3 col 1). Logistic regression showed that mothers who had had vaginal deliveries and who were over 30 years when their first child was born, were particularly at risk of stress symptoms. If age at last rather than first birth is considered the excess risk for older mothers was slightly reduced.

Overweight, having already reached menopause, higher educational qualifications, frequency of GP consultations or high levels of symptomatology and a history of bladder or kidney infections were also associated with an excess risk of stress symptoms (table 2); and all but the latter remained significant at the 5\% level after simultaneous adjustment (table 3). The risks were somewhat higher for older women using age at first birth (model 1) rather than age at last birth (model 2).

( $11 \%$ of incontinent women) and $74 \%$ of these women had had their problem for more than five years. Women who attributed their incontinence to specific urogenital problems such as genital prolapse and uterine fibroids ( $4 \%$ of incontinent women), to aging and the menopause $(5 \%)$ or to overweight ( $3 \%$ ) were more likely to report their problem had begun within the past five years. The majority of women could not give a reason or referred only to lack of muscle control or to the precipitating factor (such as coughing or exercising).
RISK FACTORS FOR URGE SYMPTOMS

Compared with those who were dry during the day and night, women who had been regular bedwetters at age 6 years were twice as likely, and those who had been day wetters were one and a half times more likely, to suffer urge symptoms at 48 years. Those who had only wet the bed occasionally had no raised risk (table 2). Regular bedwetters and day wetters were combined for further analysis because of the small numbers. 
Table 3 Predictors of stress symptoms $(n=974)$

\begin{tabular}{|c|c|c|c|c|c|c|}
\hline & $\begin{array}{l}\text { Unadjusted odds ratio } \\
(95 \% \mathrm{CI})\end{array}$ & $p$ value & $\begin{array}{l}\text { Model } 1 \text { Adjusted } \neq \\
\text { odds ratio }(95 \% \text { CI })\end{array}$ & $p$ value & $\begin{array}{l}\text { Model } 2 \text { Adjusted } \neq \\
\text { odds ratio }(95 \% \text { CI) }\end{array}$ & $p$ value \\
\hline \multicolumn{7}{|l|}{ Childbirth characteristics } \\
\hline No births & 1.0 & \multirow[t]{5}{*}{0.010} & 1.0 & \multirow[t]{5}{*}{0.002} & \multirow{5}{*}{$\mathrm{n} / \mathrm{a}$} & \\
\hline Age at first birth $\leqslant 30$ y and vaginal deliveries & $1.8(1.2,2.6)$ & & $2.0(1.3,3.0)$ & & & \\
\hline Age at first birth $\leqslant 30$ y and all caesarean deliveries & $1.0(0.44,2.5)$ & & $1.0(0.39,2.4)$ & & & \\
\hline Age at first birth $>30$ y and vaginal deliveries & $2.8(1.5,5.5)$ & & $3.1(1.5,6.0)$ & & & \\
\hline Age at first birth $>30 \mathrm{y}$ and all caesarean deliveries & $1.7(0.51,5.5)$ & & $1.7(0.61,4.6)$ & & & \\
\hline No births & 1.0 & \multirow[t]{5}{*}{0.011} & & & 1.0 & \multirow[t]{5}{*}{0.003} \\
\hline Age at last birth $\leqslant 30$ y and vaginal deliveries & $1.7(1.2,2.5)$ & & & & $2.0(1.3,3.0)$ & \\
\hline Age at last birth $\leqslant 30$ y and all caesarean deliveries & $0.8(0.31,2.2)$ & & $\mathrm{n} \backslash \mathrm{a}$ & & $0.8(0.27,2.1)$ & \\
\hline Age at last birth $>30 \mathrm{y}$ and vaginal deliveries & $2.1(1.3,3.2)$ & & & & $2.1(1.3,3.3)$ & \\
\hline Age at last birth $>30 \mathrm{y}$ and all caesarian deliveries & $1.9(0.68,5.2)$ & & & & $1.9(0.67,5.4)$ & \\
\hline \multicolumn{7}{|l|}{ Urinary or kidney infections (15-43 y) } \\
\hline No & 1.0 & \multirow[t]{2}{*}{0.097} & 1.0 & \multirow[t]{2}{*}{0.597} & & \multirow[t]{2}{*}{0.604} \\
\hline Yes & $1.3(0.95,1.8)$ & & $1.1(0.78,1.5)$ & & $1.1(0.75,1.5)$ & \\
\hline \multicolumn{7}{|l|}{ Naturally postmenopausal (by 48 y) } \\
\hline No & 1.0 & \multirow[t]{2}{*}{0.013} & 1.0 & \multirow[t]{2}{*}{0.022} & 1.0 & \multirow[t]{2}{*}{0.032} \\
\hline Yes & $0.53(0.32,0.87)$ & & $0.54(0.32,0.91)$ & & $0.57(0.33,0.95)$ & \\
\hline Body mass index ${ }^{\star}(43 y)$ & $1.2(1.0,1.4)$ & 0.022 & $1.2(1.0,1.4)$ & 0.012 & $1.2(1.0,1.4)$ & 0.012 \\
\hline Symptomatology (47-48 y) & $1.1(1.0,1.2)$ & $<0.001$ & $1.1(1.0,1.2)$ & 0.002 & $1.1(1.0,1.2)$ & 0.001 \\
\hline \multicolumn{7}{|l|}{ GP consultations ( $47 \mathrm{y}$ ) } \\
\hline Low & 1.0 & \multirow{2}{*}{$<0.001$} & 1.0 & \multirow{2}{*}{0.032} & & \multirow{2}{*}{0.032} \\
\hline High & $1.6(1.2,2.1)$ & & $1.4(1.0,1.9)$ & & $1.4(1.0,1.9)$ & \\
\hline Educational level $^{\dagger}$ & $1.2(1.1,1.4)$ & $<0.001$ & $1.3(1.2,1.5)$ & $<0.001$ & $1.3(1.2,1.5)$ & $<0.001$ \\
\hline
\end{tabular}

$\star$ Per 5 units $\left(\mathrm{kg} / \mathrm{m}^{2}\right)$. †Fitted as a continuous variable taking values 0 (no qualifications) to 4 (degree level). $\ddagger$ Adjusted for all other factors.

An excess risk of these symptoms was also seen for women who reported a history of bladder or kidney infections, a hysterectomy, high levels of symptomatology or frequent GP consultations. There was a trend with body weight $(p=0.06)$ attributable to the high rate of urge symptoms among obese women (table 2 ).

Table 4 Predictors of urge symptoms $(n=1017)$

\begin{tabular}{|c|c|c|c|c|}
\hline & \multirow[b]{2}{*}{$\begin{array}{l}\text { Unadjusted odds } \\
\text { ratio (95\% CI) }\end{array}$} & \multirow[b]{2}{*}{$p$ value } & \multirow{2}{*}{$\begin{array}{l}\text { Model } 1 \\
\begin{array}{l}\text { Adjusted } \dagger \text { odds } \\
\text { ratio }(95 \% \text { CI) }\end{array}\end{array}$} & \multirow[b]{2}{*}{$p$ value } \\
\hline & & & & \\
\hline \multicolumn{5}{|l|}{ Enuresis $(6 \mathrm{y})$} \\
\hline No & 1.0 & & 1.0 & \\
\hline Yes & $2.9(1.5,5.8)$ & 0.002 & $2.7(1.3,5.6)$ & 0.005 \\
\hline \multicolumn{5}{|c|}{ Urinary or kidney infections $(15-43 \mathrm{y})$} \\
\hline No & 1.0 & 0.123 & 1.0 & 0.372 \\
\hline Yes & $1.3(0.93,1.9)$ & & $1.2(0.82,1.7)$ & \\
\hline \multicolumn{5}{|l|}{ Hysterectomy by ( $48 \mathrm{y}$ ) } \\
\hline No & 1.0 & 0.005 & 1.0 & 0.115 \\
\hline Yes & $1.6(1.2,2.4)$ & & $1.3(0.93,2.0)$ & \\
\hline Body mass index ${ }^{\star}(43 \mathrm{y})$ & $1.3(1.2,1.4)$ & 0.003 & $1.2(0.98,1.3)$ & 0.080 \\
\hline Symptomatology (47-48 y) & $1.3(1.1,1.4)$ & $<0.001$ & $1.3(1.2,1.4)$ & $<0.001$ \\
\hline \multicolumn{5}{|l|}{ GP consultations $(47 \mathrm{y})$} \\
\hline Low & 1.0 & $<0.001$ & 1.0 & 0.467 \\
\hline High & $1.8(1.3,2.4)$ & & $1.1(0.81,1.6)$ & \\
\hline
\end{tabular}

^Per 5 units $\left(\mathrm{kg} / \mathrm{m}^{2}\right)$. †Adjusted for all other factors.

Table 5 Predictors of severe incontinence $(n=1066)$

\begin{tabular}{|c|c|c|c|c|}
\hline & \multirow[b]{2}{*}{$\begin{array}{l}\text { Unadjusted odds } \\
\text { ratio }(95 \% \text { CI) }\end{array}$} & \multirow[b]{2}{*}{$p$ value } & Model 1 & \multirow[b]{2}{*}{$p$ value } \\
\hline & & & $\begin{array}{l}\text { Adjusted } \neq \text { odds } \\
\text { ratio }(95 \% C I)\end{array}$ & \\
\hline \multicolumn{5}{|l|}{ Enuresis $(6 \mathrm{y})$} \\
\hline No & 1.0 & & & \\
\hline Yes & $3.5(1.6,7.7)$ & 0.001 & $2.9(1.3,6.9)$ & 0.012 \\
\hline Number of children & $1.2(1.0,1.5)$ & 0.045 & $1.2(0.99,1.5)$ & 0.065 \\
\hline \multicolumn{5}{|c|}{ Urinary or kidney infections (15-43 y) } \\
\hline No & 1.0 & 0.028 & 1.0 & 0.083 \\
\hline Yes & $1.7(1.1,2.8)$ & & $1.6(0.94,2.6)$ & \\
\hline Body mass index ${ }^{\star}(43 \mathrm{y})$ & $1.5(1.2,1.8)$ & $<0.001$ & $1.3(1.1,1.6)$ & 0.013 \\
\hline Symptomatology (47-48 y) & $1.3(1.2,1.4)$ & $<0.001$ & $1.2(1.1,1.3)$ & 0.003 \\
\hline \multicolumn{5}{|l|}{ GP consultations $(47 \mathrm{y})$} \\
\hline Low & 1.0 & $<0.001$ & 1.0 & 0.020 \\
\hline High & $2.7(1.7,4.3)$ & & $1.8(1.1,2.9)$ & \\
\hline Educational level† & $0.77(0.65,0.91)$ & $<0.001$ & $0.86(0.72,1.0)$ & 0.126 \\
\hline
\end{tabular}

*Per 5 units $\left(\mathrm{kg} / \mathrm{m}^{2}\right)$. †Fitted as a continuous variable taking values 0 (no qualifications) to 4 (degree level). $\ddagger$ Adjusted for all other factors.
A final model that simultaneously adjusted for all significant risk factors revealed an excess of urge symptoms among women who suffered from childhood enuresis or reported high rates of recent symptomatology (table 4, model 1). The odds ratios for the other factors were attentuated once these two had been taken into account.

RISK FACTORS FOR SEVERE INCONTINENCE Severe incontinence was related to childhood enuresis (not including occasional bedwetters), parity, a history of bladder or kidney infections, overweight, high symptomatology and frequent GP visits (table 2). It was more prevalent among less educated women. Simultaneous adjustment showed some attentuation in the odds ratios for most of these risk factors (table 5, model 1).

\section{Discussion}

In a general population sample of 1333 women aged 48 years just over half the women reported some incontinence in the past year. Some studies have reported prevalence figures for women aged $45-54$ years as high as $60 \%^{23}{ }^{11}$ whereas others have been as low as $10 \% .{ }^{10}$ Estimates of severe incontinence are more consistent than those for any loss of urine and our figure of $9 \%$ is within the expected range. ${ }^{24}$ The study was limited in its reliance on self reported stress and urge symptoms, rather than a diagnosis of stress or urge incontinence based on clinical and urodynamic examinations. Almost $90 \%$ of women with urge symptoms also reported stress symptoms; inevitably some of them would have been diagnosed with pure stress incontinence. Thus we cannot assume our findings are generalisable to women with detrusor instability or genuine stress incontinence.

CHILDHOOD ENURESIS

This is the first prospective study to show an association between childhood enuresis and adult urinary incontinence. Compared with 
previous population studies that have relied on retrospective data ${ }^{1316}$ the association is stronger, perhaps because of the ability to distinguish between regular and occasional bedwetting. Childhood enuresis may be physical or psychological in origin. ${ }^{25}$ We suspect there may be a common aetiological factor for childhood enuresis and urge incontinence. Adult women with detrusor instability commonly report childhood enuresis ${ }^{26}$ and studies of children show that bladder instability is more common in diurnal enuretics than nocturnal enuretics. ${ }^{27}$ It has been suggested that urge incontinence in some adults represents a constitutional inadequacy in the neurological reflex mechanisms. ${ }^{13}$ Or it is possible that the link between childhood enuresis and adult incontinence is attributable to a failure to learn to achieve normal bladder control at the time of "potty training" ${ }^{25}$ Certainly adult women with detrusor instability have been shown to toilet train their children differently from the general female population. ${ }^{28}$ Alternatively, both childhood enuresis and adult urge incontinence may be markers of psychological distress. ${ }^{28}$ Day wetting in children is associated with behavioural problems and is particularly common among girls. ${ }^{29}{ }^{30}$ In this cohort those who experienced anxiety provoking events in the first four years of life were more likely to suffer from childhood enuresis. ${ }^{31}$ In the cohort's adult life, childhood enuresis is a predictor of suicide and accidental death in men between 15 and 50 years ${ }^{32}$ and of anxiety and depression in women at 36 years. ${ }^{33}$ These women were more likely to report high symptomatology in midlife ${ }^{20}$ that was strongly associated with reports of incontinence (table 2), and this may explain why the relation between childhood enuresis with severe incontinence (and to a lesser extent with urge symptoms) was attentuated in the fully adjusted models.

CHILDBEARING

This study found that nulliparous women in midlife had the lowest risk of stress symptoms and that the risk of severe incontinence increased with parity. The relation with stress symptoms may have been obscured by the high proportion of women with only mild symptoms. Vaginal deliveries at older ages were associated with a particularly high risk of stress symptoms. Previous studies have shown that parous women suffer more stress incontinence than nulliparous women ${ }^{13} 9^{11-13}$ 34-37 $^{-3}$ and most have also found that increasing parity raises the risk further. ${ }^{13934-37}$ The number of caesarean deliveries in this group was too small to draw conclusions; two postpartum studies found them to be protective ${ }^{38} 39$ but a relation with mode of delivery has not been observed in most population samples. ${ }^{111-13} 37$ Thus it is still not entirely clear whether excess stress incontinence is attributable to pregnancy itself or to damage sustained by the mother at delivery, but it is most likely to be a combination of both.

A study of women in the postpartum period has previously shown that women aged over 30 years had a raised risk of stress incontinence ${ }^{38}$ but a survey of a Danish population sample ${ }^{14}$ found the highest prevalence of incontinence among those who had been teenage mothers. The authors of this second study suggested that the influence of childbirth faded with age because in their sample older women aged over 45 years only had an excess risk of stress incontinence if they had given birth to three or more children. Thus the older first time mothers in our study may have had more stress incontinence because there had been a shorter time for reparative processes to occur. The slightly weaker relation between age at the birth of the last child and incontinence in our study did not support this hypothesis.

ADULT BODY WEIGHT

Our findings revealed severe incontinence and stress symptoms were associated with a measure of body weight taken five years earlier. This adds to the findings of previous studies that have not included measured height and weight, ${ }^{15}$ or have not adjusted for other possible risk factors except age. ${ }^{12}$ In our study the raised risk for urge symptoms was restricted to obese women and was considerably attentuated in the fully adjusted model: it may be that both are because of a common underlying anxiety state.

HYSTERECTOMY

Most studies, ${ }^{9}{ }^{40-42}$ but not all, ${ }^{311}$ have shown some excess risk of urinary incontinence with hysterectomy. In this study the considerable attentuation in the relation between hysterectomy and urge symptoms after allowing for recent general symptomatology may be attributed to the tendency for these women to report more symptoms of various types. ${ }^{20}$

MENOPAUSE

It has been suggested that irritative urinary symptoms, including urge incontinence, may be related to oestrogen deficiency. ${ }^{43}$ Some cross sectional studies suggest that the risk of stress incontinence peaks during the late 40 s and early $50 \mathrm{~s}^{344}$ and thereafter declines whereas the risk of urge incontinence increases steadily after middle age, ${ }^{45}$ but the evidence is inconsistent. ${ }^{38946}$ In our study the small group of postmenopausal women did not report an excess of urge symptoms but they did report the least stress symptoms. Most of these women were recently postmenopausal and urge incontinence may be a later manifestation of oestrogen deficiency. We are continuing to follow up these women up annually, which will allow us to assess longitudinally the robustness of these findings.

GENERAL HEALTH AND HEALTH CARE

Incontinence can be a direct consequence of certain medical conditions and may explain the strong association between incontinence and general symptomatology. Alternatively, there may be a group of women who consistently report more health problems of all kinds, including urinary problems. Studies show that women suffering incontinence had higher than average neuroticism scores ${ }^{13}$ and greater anxiety and depression than the general population, 
similar to that of women with other chronic conditions. ${ }^{47}$ It is difficult to disentangle direct effects from the contribution made by differential reporting, but given the strength of associations between general symptomatology and incontinence observed in this population, studies that focus exclusively on urinary problems and do not consider other health outcomes may overestimate the size of the relation between incontinence and its risk factors.

\section{SOCIOECONOMIC STATUS}

The prevalence of stress symptoms in our study was highest amongst the best educated women but there was a strong inverse educational gradient in the proportion of women with severe incontinence. This suggests that better educated women may have a lower threshold for reporting mild incontinence, either because it contrasts with their better health overall, ${ }^{48} 49$ or because they notice these symptoms as they are more likely to particpate in sports activities. $^{50}$ They also may have been made more aware that incontinence is a common problem among middle aged women from the increasing press coverage given to stress incontinence in particular over recent years and appreciate that something can be done about it.

In conclusion, urinary incontinence is a common problem among middle aged women. This prospective study supports the postulated link between childhood enuresis and adult incontinence. Childbearing has long term adverse effects, particularly for older mothers, and overweight is a common risk factor.

The authors would like to thank Professor Michael Wadsworth for his comments on earlier drafts of this paper.

Funding: Medical Research Council

Conflicts of interest: none.

1 Thomas TM, Plymat KR, Blannin J, et al. Prevalence of urinary incontinence. BMF 1980;281:1243-5.

2 Yarnell JWG, Voyle GJ, Richards CJ, et al. The prevalence and severity of urinary incontinence in women. $\mathscr{f}$ Epidemiol and severity of urinary incontinence

3 Jolleys JV. Reported prevalence of urinary incontinence in women in a general practice. BMf 1988;296:1300-2

4 Holst $\mathrm{K}$, Wilson PS. The prevalence of female urinary incontinence and reasons for not seeking treatment. NZ Med $\mathcal{F} 1988 ; 101: 756-8$.

5 Elving 1, Foldspang A, Lam G W, et al. Descriptive epidemiology of urinary incontinence in 3100 women age 30-59. Scand f Urol Nephrol Suppl 1989;125:37-43

6 Herzog AR, Fultz NH. Prevalence and incidence of urinary incontinence in community-dwelling populations. F $\mathrm{Am}$ Geriatr Soc 1990;38:273-81

7 O'Brien J, Austin M, Sethi P, et al. Urinary incontinence: prevalence, need for treatment, and effectiveness of prevalence, need for treatment, and effectiv

8 Reckers H, Drogendijk AC, Valkenburg HA, et al. The menopause, urinary incontinence and other symptoms of menopause, urinary incontinence and other symptom
the genito-urinary tract. Maturitas 1992;15:101-11.

9 Milsom I, Ekelund P, Molander U, et al. The influence of age, parity, oral contraception, hysterectomy and menopause on the prevalence of urinary incontinence in women. F Urol 1993;149:1459-62.

10 Brocklehurst JC. Urinary incontinence in the community analysis of a MORI poll. BMF 1993;306:832-4.

11 Harrison GL, Memel DS. Urinary incontinence in women its prevalence and its management in a health promotion clinic. Br F Gen Pract 1994;44:149-52.

12 Iosif S, Henrikson L, Ulmsten U. The frequency of disorders of the lower urinary tract, urinary incontinence in particular, as evaluated by a questionnaire survey in a gynecological health control population. Acta Obstet Gynecol Scand 1981;60:71-6

13 Yarnell JW, Voyle GJ, Sweetnam PM, et al. Factors associated with urinary incontinence in women. $\mathcal{F}$ Epidemiol Community Health 1982;36:58-69.

14 Foldspang A, Mommsen S, Lam GW, et al. Parity as a correlate of adult female urinary incontinence prevalence. $\mathcal{F}$ relate of adult female urinary incontinence preva
Epidemiol Community Health 1992;46:595-600.
15 Mommsen S, Foldspang A. Body mass index and adult female urinary incontinence. World f Urol 1994;12:319-22. Foldspang A, Mommsen S. Adult female urinary incontinence and childhood bedwetting. F Urol 1994;152:85-8.

17 Wadsworth MEJ. The imprint of time:childhood, history and adult life. Oxford: Oxford University Press, 1991.

18 Wadsworth MEJ, Mann SL, Rodgers B, et al. Loss and representativeness in a 43 year follow-up of a national birth cohort. F Epidemiol Community Health 1992;46:300-4.

19 Wadsworth MEJ, Kuh DJL. Childhood influences on adult health: a review of recent work from the British 1946 national birth cohort study, the MRC National Survey of Health and Development. Paediat Perinat Epidemiol 1997; 11:2-20.

20 Kuh DJL, Wadsworth MEJ, Hardy R. Women's health in midlife, the influence of the menopause, social factors and health in earlier life. Br f Obstet Gynaecol 1997;107:923-33.

21 Braddon F M, Rodgers B, Wadsworth MEJ, et al. Onset of obesity in a 36 year birth cohort study. BMF 1986;293:299303.

22 Colhoun H, Prescott-Clarke P. Health Survey for England 1994. Volume I: Findings. London: HMSO, 1996.

23 Department of Education and Science. Burnham Further Education Committee Grading Courses 1972. London: HMSO, 1972

24 Kelleher C. Epidemiology and classification of urinary incontinence. In: Cardozo L, ed. Urogynecology. New York: Churchill Livingstone, 1997.

25 Burton G. Nocturnal enuresis. In: Cardozo L, ed. Urogynecology. New York: Churchill Livingstone, 1997.

26 Moore K, Richmond DH, Parys BT. Sex distribution of adult idiopathic detrusor instability in relation to childhood bedwetting. Br f Urol 1991;68:479-82

27 Mayo ME, Burns MW. Urodynamic studies in children who wet. Br F Urol 1990;5:641-5.

28 Burton G, Wise B, Cardozo LD, et al. Detrusor instability: is it inherited or just "passed on"? Neurol Urodyn 1992;11: 458-9.

29 Rutter M, Yule W, Graham P. Enuresis and behavioural deviance: some epidemiological considerations. In: Kolvin I, Mackeith RC, Meadow SR. eds. Bladder control and enuresis. London:Heinemann, 1973:137-47.

30 Blomfield JM, Douglas JWB. Bedwetting:prevalence among children aged 4-7 years. Lancet 1956;i:850-2.

31 Douglas JWB. Early disturbing events and later enuresis. In: Kolvin I, Mackeith RC, Meadow SR, eds. Bladder control and enuresis. London:Heinemann, 1973:109-17.

32 Neelemann J, Wessely S, Wadsworth M. Predictors of suicide, accidental death, and premature natural death in a general-population birth cohort. Lancet 1998;351:93-7.

33 Rodgers B. Behaviour and personality in childhood as predictors of adult psychiatric disorder. 7 Child Psychol Psychiatry 1990;31:393-414.

34 Crist T, Shingleton HM, Koch GG. Stress incontinence and the nulliparous patient. Obstet Gynecol 1972;40:13-17

35 Sommer P, Bauer T, Nielsen KK, et al. Voiding patterns and prevalence of incontinence in women. A Questionnaire survey. Br f Urol 1990; 66:12-15

36 Turan C, Zorlu CG, Hancerliogullari N, et al. Urinary incontinence in women of reproductive age. Gynecol Obstet Invest 1996;41:132-4.

37 Nygaard I, DeLancey JOL, Arnsdorf L, et al. Exercise and incontinence. Obst Gynecol 1990;75:848.

38 MacArthur C, Lewis M, Bick D. Stress incontinence after childbirth. Br f Midwifery 1993;1:207-15.

39 Wilson PD, Herbison RM, Herbison GP. Obstetric practice and the prevalence of urinary incontinence three months after delivery. Br f Obstet Gynaecol 1996;103:154-61.

40 Iosif C S, Bekassy Z, Rydhstrom H. Prevalence of urinary incontinence in middle-aged women. Int $\mathcal{F}$ Gynecol Obstet 1988;26:255-9.

41 Griffith-Jones MD, Jarvis GJ, McNamara HM. Adverse urinary symptoms after total abdominal hysterectomy - fact or fiction? Br F Urol 1991;67:295-7.

42 Mommsen S, Foldspang A, Elving L, et al. Association between urinary incontinence in women and a previous history of surgery. $\mathrm{Br} \mathcal{F}$ Urol 1993;72:30-7.

43 Cardozo LD, Versi E. Estrogens and the lower urinary tract. In: Ashe RH, Studd JWW, eds. Annual progress in reproductive medicine. London: Parthenon Press, 1993:311-24.

44 Osborne JL. Post-menopausal changes in micturition habits and in urine flow and urethral pressure studies. In: Campbell S, ed. The management of the menopause and postmenopausal years. London: MTP Publications, 1976: 285-9.

45 Kondo A, Kato K, Saito M, et al. Prevalence of hand-washing urinary incontinence in females in comparihand-washing urinary incontinence in females in compari-
son with stress and urge incontinence. Neurol Urodyn 1990; Son with stre

46 Versi E, Cardozo L, Studd J, et al. Urinary disorders and the menopause. Menopause 1995;2:89-95.

47 Kelleher CJ, Cardozo LD, Khullar V. Urinary incontinence and neurotic illness: fact, fiction or fabrication? Neurol Urodyn 1995;13:372-4.

48 Kuh DJL, Wadsworth MEJ. Physical health status at 36 years in a British national birth cohort. Soc Sci Med 1993; 37:905-16.

49 Kuh D, Stirling S. Socioeconomic variation in admission for diseases of female genital system and breast in a national cohort aged 15-43. BM7 1992;311:840-3.

50 Kuh DJL, Cooper C. Physical activity at 36 years: patterns and childhood predictors in a longitudinal study. $f$ Epidemiol Community Health 1992;46:114-19. 